\title{
Isolation and genetic diversity of Gambusia hubbsi (mosquitofish) populations in blueholes on Andros Island, Bahamas
}

\author{
MALCOLM D. SCHUG*, J ERRY F. DOWNHOWER, LUTHER P. BROWN $\dagger$, DUSTIN B. \\ SEARS $\$$ \& PAUL A. FUERST: \\ Department of Zoology, 1735 Neil Avenue, The Ohio State University, Columbus, Ohio 43210, $†$ Department of \\ Biology, George Mason University, Fairfax, Virginia 22030 and \$Department of Molecular Genetics, 484 West 12th \\ Avenue, The Ohio State University, Columbus, $\mathrm{OH} 43210$, U.S.A.
}

\begin{abstract}
Among the many freshwater habitats occupied by the mosquitofish (Gambusia hubbsi) on Andros Island, Bahamas, are blueholes: vertical caves that filled with water as sea levels rose during the past 15000 years. At the present time, many of the blueholes on Andros Island appear to be highly isolated habitats analogous to islands. However, geographical distance among blueholes and the geological history of bluehole formation may also affect the genetic structure of $G$. hubbsi populations in blueholes. Thirty-two isozyme loci in 14 G. hubbsi populations inhabiting blueholes and three inhabiting surface-water habitats were assayed to gain insight into the effects of geological history and geographical distribution on population structure. Genetic structure among populations is high and significant $\left(F_{\mathrm{ST}}=0.38-0.4\right)$ and Nei's genetic distance $(D)$ is low among all populations. Although $G$. hubbsi populations are closely related, bluehole geology imposes significant barriers to gene flow. A pattern of isolation-by-distance was not evident in the genetic data. Furthermore, none of the bluehole populations appears to be a source from which other bluehole populations were founded. Rather, they appear to be 'sinks' into which migration may occur rarely. Genetic drift appears to have had a profound effect on allozyme allele frequencies in the G. hubbsi populations that were sampled. Local population structure measured by allozymes appears to be more heavily influenced by historical population dynamics and stochastic migration than by geographical locality or age of the blueholes.
\end{abstract}

Keywords: allozyme, bluehole, Gambusia hubbsi, isolation-by-distance, mosquitofish, population structure.

\section{Introduction}

On Andros Island, Commonwealth of the Bahamas, the mosquitofish (Gambusia hubbsi) inhabits many aquatic habitats including freshwater blueholes. Blueholes are water-filled vertical caves formed by geological processes, such as dissolution and fracturing of the bank margin, as sea levels fluctuated historically (Mylroie \& Carew, 1988, 1995, 1997). The depth of blueholes on Andros Island ranges from $5 \mathrm{~m}$ to over $100 \mathrm{~m}$, and many are surrounded by stands of Bahamian pine forest. There is no flowing water on Andros except for tidal creeks. Thus, blue-

${ }^{*}$ Correspondence and present address: Section of Genetics and Development, Biotechnology Building, Cornell University, Ithaca, NY 14853, U.S.A. holes are not part of a surface-water drainage basin, and most are not connected by surface water. Rather, these caves open into the groundwater supply of the island: a freshwater lens floating on top of saltwater that permeates the foundation of the island. Because sea levels were over $100 \mathrm{~m}$ lower than today at the height of the most recent glacial maximum, most blueholes were dry 15000-17000 years ago and filled to present levels as the freshwater lens rose (Boardman et al., 1989; Fairbanks, 1989; Mylroie \& Carew, 1995). Blueholes appear to be highly isolated habitats analogous to islands, geographically isolated lakes in temperate regions or even hydrothermal vents that occur as isolated habitats at distant locations on suboceanic ridges (e.g. Black et al., 1994). The earliest time at which fish 
such as G. hubbsi could have colonized a particular bluehole is determined by its depth. Thus, the temporal and geographical degree of isolation among $G$. hubbsi populations is well defined, and populations of $G$. hubbsi inhabiting these blueholes are very well suited to studies of population structure.

Because of the apparent isolation of bluehole habitats, migration among sites by $G$. hubbsi may be highly restricted. This and significant life history differences observed among populations (unpubl. data; Brown \& Downhower, 1993) indicate that there is potential for adaptation to local ecological conditions within blueholes. However, Gambusia species in the United States are highly mobile (Wooton et al., 1988; Meffe \& Snelson, 1989). Furthermore, G. hubbsi on Andros Island are relatively common inhabitants of surface water, such as lakes, ditches and tidal creeks. Although surface water does not flow directly into or from the blueholes studied, it is close enough to some of the blueholes so that migration may occur occasionally. Thus, the degree and patterns of migration imposed on $G$. hubbsi by the geological characteristics of blueholes is unclear.

We were motivated by the geological and geographical characteristics of blueholes and the significant phenotypic differences among G. hubbsi populations to explore models of population structure and the extent and mode of dispersal among $G$. hubbsi populations on Andros Island. We focus on the following questions. (1) Are bluehole populations of $G$. hubbsi on Andros Island highly structured?; (2) Does the genetic structure of populations conform to a pattern of isolation-by-distance?; (3) Has the historical availability of bluehole habitats had a significant influence on the pattern of colonization? In addition to 14 blueholes, two surfacewater sites were sampled to compare levels of genetic variation and differentiation with recently derived populations of $G$. hubbsi not inhabiting blueholes. Genetic variation was also examined in a population from Lake Cunningham on New Providence Island, the nearest neighbouring island where migration to and from Andros Island populations has not occurred in recent times.

\section{Methods}

\section{Collections and genetic analysis}

During August 1993 and June 1994, adult G. hubbsi were collected by seining from 14 blueholes, two surface-water habitats on northern Andros Island
(Fig. 1) and from the type locality (Rauchenberger, 1989), Lake Cunningham, New Providence Island. Depths of blueholes are from Proud-Love (1984) or were measured by drop-lines and a depth finder. Specimens were preserved in liquid nitrogen and subsequently stored at $-80^{\circ} \mathrm{C}$.

The anterior of each fish, including the head, liver and some of the body were homogenized in approximately $0.3 \mathrm{~mL}$ of buffer $(0.01 \mathrm{M}$ Tris, $\mathrm{pH} 7.0,0.001 \mathrm{M}$ EDTA, $1.0 \mathrm{~mm} \beta$-mercaptoethanol, 0.01 per cent Triton-X, 0.002 per cent NADP). The homogenate was extracted with $0.5 \mathrm{~mL}$ of toluene, spun for $10 \mathrm{~min}$ in a microfuge, and the supernatant was used for electrophoresis. Methods for electrophoresis were as described previously (Selander et al., 1971) using 11.5 per cent hydrolysed potato starch (Sigma Chemical, St Louis, MO, U.S.A.). Nineteen stains representing 32 presumptive isozyme loci were chosen from more than 50 stain/buffer combinations tested for consistent resolvability. The following enzymes were resolved with a continuous Tris-citrate 8.0 buffer system: aspartate aminotransferase (EC 2.6.1.1, AAT-1, -2), adenylate kinase (2.7.4.3, AK-1, -2), fructose-biphosphatase (3.1.3.11, FBP-1, -2), glucose dehydrogenase (1.1.1.118, GDH-1, -2), glucose-6-phosphate dehydrogenase (1.1.1.49, G6PD), glycerol-3-phosphate dehydrogenase (1.1.1.8, GPD-1, -2), hexokinase (2.7.1.1, HK), isocitrate dehydrogenase (1.1.1.42, IDH), L-idotol dehydrogenase (1.1.1.14, IDDH), malate dehydrogenase (1.1.1.37, MDH-1, -2), malic acid (1.1.1.40, ME-1, -2), mannose-6-phosphate isomerase (5.3.1.8, MPI-1, -2), phosphogluconate dehydrogenase (1.1.1.43, PGD), phosphoglucomutase (5.4.2.2, PGM), pyruvate kinase (2.7.1.40, PK-1, -2), superoxide dismutase (1.15.1.1, SOD). A discontinuous Poulik buffer resolved creatine kinase (2.7.3.2, CK-1, -2), glucose-6-phosphate isomerase (5.3.1.9, GPI-1, -2) and L-lactate dehydrogenase (1.1.1.27, LDH-1, $-2,-3)$. Staining recipes for FBP, GDH and IDDH followed Murphey et al. (1996); LDH, PGM, and SOD followed Morizot (1993); and the rest followed Pasteur (1988). A reference sample from a previously analysed population was run on each gel. In cases in which resolvability remained unclear, the locus was not scored for that individual.

\section{Statistical analysis}

Observed and expected heterozygosities were calculated with BIOSYS-1 (Swofford \& Selander, 1981) using genotype frequencies. Chi-squared tests with pooling and Levene's correction for sample size 
(Levene, 1949) were used to test for deviations of observed genotype frequencies from expected Hardy-Weinberg equilibrium frequencies. Loci were considered polymorphic if the frequency of the most common allele was $\leq 0.95$. Genetic structure was measured using $F_{\mathrm{ST}}$ and $\theta$ (Wright, 1973; Weir \& Cockerham, 1984).

Straight-line geographical distances $(\mathrm{km})$ were measured from a topographical map. The congruence between average number of migrants per generation $(M$; Slatkin's analogue of $N m$; Slatkin, 1993) and geographical distances was examined using DIST (Slatkin, 1993). The significance of the correlation was evaluated with Mantel's test and Hope's correction factor using the $\mathrm{R}$ PACKAGE (Legendre \& Vaudor, 1991). A genetic distance matrix was imported into MEGA (Kumar et al., 1993) to generate a dendrogram from Nei's unbiased genetic distance values (Nei, 1978) using the neighbour-joining algorithm (Saitou \& Nei, 1987).

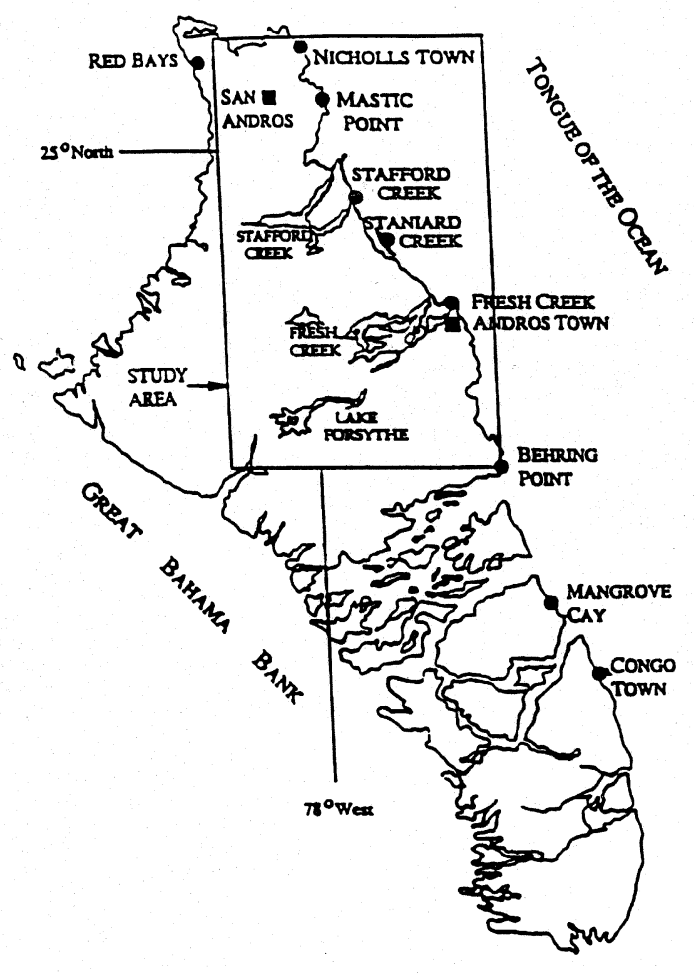

Fig. 1 Study sites on North Andros Island, Bahamas.

\section{Results}

\section{Genetic variation}

Of 32 loci examined, 21 are polymorphic in one or more populations. In general, low-frequency alleles are common at many loci, whereas $\mathrm{Me}-1, \mathrm{Mpi}-1$, $P g d-1$ and $P k-1$ have moderate to high levels of variation. A total of 53 alleles are observed, of which 16 (30.2 per cent) are unique to a single population. Fifteen of these population-specific alleles occur at a frequency of $<10$ per cent. Eight populations have no unique alleles, five have one unique allele, two have two unique alleles and two have three unique alleles. Seven (13.2 per cent) of the 53 alleles are rare (frequency of $\leq 5$ per cent within a population) but shared between two or three populations. Fixation or near fixation of an alternative allele is present in two cases. First, the $C$ allele of $P k-1$ is fixed in the New Providence Island population and occurs elsewhere only as a rare allele in the West

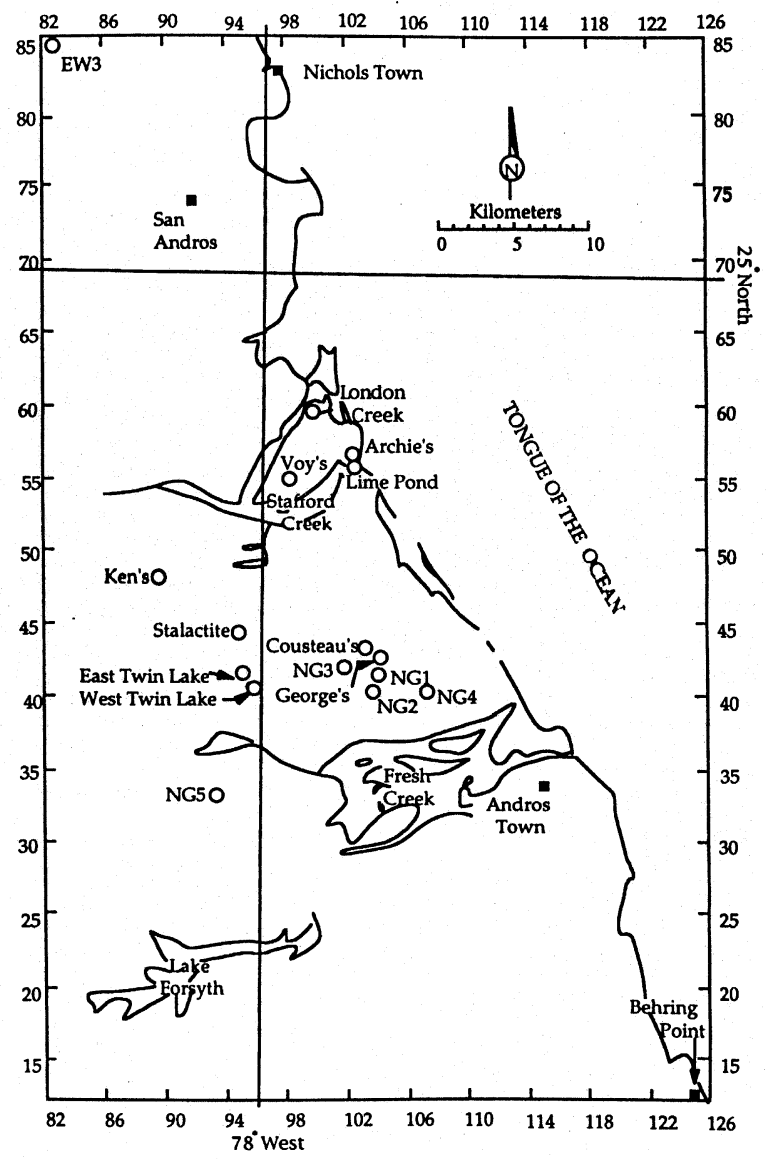

(C) The Genetical Society of Great Britain, Heredity, 80, 336-346. 
Twin Lake population. Secondly, the $B$ allele of $G p d-1$ is nearly fixed in the Stalactite population and does not appear in the other populations. None of the loci are polymorphic in all populations. Four loci exhibit frequencies significantly different from Hardy-Weinberg expectations. All of these loci have rare alleles accounting for the deviation.

Summary statistics of genetic variation are given in Table 1. Mean number of alleles per locus ranges from the monomorphic samples in NG4, Archie's and East Twin Lake to $1.3 \pm 0.01$ for Ken's, $1.3 \pm 0.1$ for Stalactite and $1.3 \pm 0.1$ for West Twin Lake. Stalactite shows the highest proportion of polymorphic loci (17.1 \pm 0.1$)$, and three populations have no polymorphic loci. Levels of heterozygosity measured by Nei's unbiased estimate (Nei, 1978) range from zero in the Archie's, and NG4 populations to 0.06 in the Stalactite population. Heterozygosity and percentage polymorphic loci for three populations from surface-water sites (Lime Pond, London Creek and New Providence Island) are similarly low. There is no indication that alleles in bluehole populations are a subset of alleles from populations in surface-water habitats. Values of $F_{\text {IS }}$ are not significantly different from zero, suggesting that inbreeding has no measurable effect on allele frequencies.

\section{Population structure}

Measures of population structure were calculated with and without the population from New Providence Island (Table 2). Significantly different and high levels of population structure occur at 16 of the 21 polymorphic loci. A significant amount of the total genetic variation is attributable to variation among populations. A small amount of additional structure is added when the New Providence population is included in the analysis. Excluding populations from surface-water habitats on Andros Island makes no appreciable difference.

$\mathrm{Nm}$, a measure of the average number of individuals exchanged between populations per generation, can be calculated as $\left(1-F_{\mathrm{ST}}\right) / 4 F_{\mathrm{ST}}$. A value of $\mathrm{Nm}$ equal to one is sufficient, in theory, to prevent genetic differentiation by genetic drift alone (Wright, 1973). $\mathrm{Nm}$ is less than one for all populations of $G$. hubbsi combined, with and without the New Providence sample included in the analysis (Table 2). Pairwise comparisons of $M$ (Slatkin's analogue of $\mathrm{Nm}$ derived from $\theta$; Slatkin, 1993) between populations indicate that migration among some blueholes may be more frequent than among others (Table 3a). This may reflect different rates of migration among blueholes at different geographical

Table 1 Genetic variability at 32 loci for Gambusia hubbsi populations (Standard errors in parentheses)

\begin{tabular}{lccrc}
\hline & $\begin{array}{c}\text { Mean } \\
N \text { per } \\
\text { locus }\end{array}$ & $\begin{array}{c}\text { Mean no. } \\
\text { alleles/ } \\
\text { locus }\end{array}$ & $\begin{array}{c}\text { Percentage } \\
\text { loci } \\
\text { polymorphic }\end{array}$ & $\begin{array}{c}\text { Mean } \\
\text { heterozygosity }\end{array}$ \\
\hline New Providence & $29.1(1.5)$ & $1.1(0.0)$ & $0.0(0.0)$ & $0.003(0.002)$ \\
Archie's & $25.0(0.0)$ & $1.0(0.0)$ & $0.0(0.0)$ & $0.000(0.000)$ \\
Cousteau's & $50.0(0.0)$ & $1.1(0.01)$ & $5.7(0.1)$ & $0.010(0.006)$ \\
EW3 & $48.9(0.8)$ & $1.2(0.10)$ & $2.9(0.1)$ & $0.012(0.005)$ \\
George's & $39.7(2.1)$ & $1.2(0.10)$ & $14.3(0.1)$ & $0.022(0.010)$ \\
Ken's & $49.0(0.1)$ & $1.3(0.01)$ & $8.6(0.1)$ & $0.023(0.010)$ \\
Lime Pond & $25.0(0.0)$ & $1.1(0.0)$ & $5.7(0.0)$ & $0.010(0.007)$ \\
London Creek & $43.1(1.7)$ & $1.1(1.10)$ & $8.6(0.1)$ & $0.037(0.020)$ \\
NG1 & $50.0(0.0)$ & $1.1(0.10)$ & $11.4(0.1)$ & $0.037(0.020)$ \\
NG2 & $24.9(0.1)$ & $1.1(0.1)$ & $8.6(0.1)$ & $0.033(0.018)$ \\
NG3 & $40.8(1.9)$ & $1.1(1.10)$ & $11.4(0.1)$ & $0.038(0.019)$ \\
NG4 & $50.0(0.0)$ & $1.0(0.0)$ & $0.0(0.0)$ & $0.000(0.000)$ \\
NG5 & $49.8(0.1)$ & $1.1(0.1)$ & $11.4(0.1)$ & $0.019(0.010)$ \\
Stalactite & $46.0(1.3)$ & $1.3(1.10)$ & $17.1(0.1)$ & $0.060(0.025)$ \\
Voy's & $25.0(0.0)$ & $1.1(0.0)$ & $5.7(0.0)$ & $0.009(0.006)$ \\
East Twin Lake & $26.0(0.0)$ & $1.0(0.0)$ & $2.9(0.0)$ & $0.008(0.008)$ \\
West Twin Lake & $40.2(0.7)$ & $1.3(0.1)$ & $14.3(0.1)$ & $0.042(0.017)$ \\
\hline
\end{tabular}


distances from one another. If blueholes in close proximity have a higher exchange of migrants than more distant blueholes, a pattern of isolationby-distance is expected. To test for this possibility, the matrix of geographical distances was compared with the matrix of Slatkin's pairwise $M$-values between blueholes (Table 3a). If isolationby-distance exists, a negative correlation is expected. In contrast, the correlation is positive and significant (Fig. 2; $r=0.087$, Mantel $t=2.65, P=0.004$ ). The correlation between Nei's unbiased genetic distance and geographical distance is also expected to be positive for a pattern of isolation-by-distance. In contrast, it is negative and not significant $(r=-0.20, \quad N=91, \quad P=\mathrm{NS} ; \quad$ Mantel $t=-1.06$, $P=$ NS).

Table 2 Genetic structure of polymorphic allozyme loci among 16 populations of Gambusia hubbsi on Andros Island and from the same Andros Island populations with the addition of one population from New Providence Island (total)

\begin{tabular}{lll}
\hline Locus & $\begin{array}{c}\mathrm{F}_{\mathrm{ST}} \\
\text { Andros Island }\end{array}$ & $\begin{array}{c}F_{\mathrm{ST}} \\
\text { Total }\end{array}$ \\
\hline Aat-1 & $0.019^{*}$ & $0.018^{*}$ \\
Ck-1 & 0.001 & 0.001 \\
Ck-2 & $0.045^{*}$ & $0.039^{*}$ \\
G6pd & $0.245^{*}$ & $0.223^{*}$ \\
Gpd-1 & $0.962^{*}$ & $0.957^{*}$ \\
Gpd-2 & 0.000 & 0.000 \\
Gpi-1 & $0.076^{*}$ & $0.067^{*}$ \\
Gpi-2 & $0.068^{*}$ & $0.060^{*}$ \\
Iddh & 0.001 & 0.001 \\
Ldh-3 & $0.065^{*}$ & $0.057^{*}$ \\
Mdh-1 & $0.186^{*}$ & $0.168^{*}$ \\
Mdh-2 & $0.246^{*}$ & $0.223^{*}$ \\
Me-1 & $0.150^{*}$ & $0.139^{*}$ \\
Me-2 & $0.112^{*}$ & $0.100^{*}$ \\
Mpi-1 & $0.161^{*}$ & $0.147^{*}$ \\
Mpi-2 & 0.011 & 0.009 \\
Pgd-1 & $0.155^{*}$ & $0.140^{*}$ \\
Pgm-1 & $0.017^{*}$ & $0.015^{*}$ \\
Pk-1 & $0.524^{*}$ & $0.590^{*}$ \\
Pk-3 & $0.101^{*}$ & $0.090^{*}$ \\
Sod-1 & 0.012 & 0.009 \\
Total F $F_{\mathrm{ST}}$ & 0.359 & 0.380 \\
Total $\theta$ & $0.380^{*}$ & $0.403^{*}$ \\
Nm & 0.408 & 0.370 \\
\hline For & &
\end{tabular}

For individual loci: ${ }^{*} \chi^{2}$ goodness-of-fit $P<0.05$. For total $\theta: * 95$ per cent confidence intervals did not overlap zero and are thus significant.

\section{Patterns of relationship and age of blueholes}

Three approaches were used to determine if the patterns of genetic variation observed are consistent with the hypothesis that G. hubbsi colonized blueholes as sea levels rose. First, we examined the relationship between Nei's genetic distance (Fig. 3a; Table $3 b$ ) and the expected pattern of relationship based on depth of blueholes and the geographical distance to the nearest neighbouring bluehole as each bluehole filled with water historically (Fig. 3b; Table $3 \mathrm{~b}$ ). The expected relationships of populations based on the depth of the blueholes were generated by adding each bluehole to a dendrogram in the historical order that they filled with water. At each branch, the most likely source was the closest bluehole geographically. A matrix was generated from Fig. 3b representing the earliest time (depth) at which each bluehole could have been colonized by G. hubbsi from the next-deepest bluehole on the same branch of the dendrogram (Table 3b). The $M$ matrix and the depth matrix are not significantly correlated $(r=0.02$, Mantel $t=0.22, P=\mathrm{NS})$. Similarly, the $D$ matrix (Table $3 \mathrm{a}$ ) and the depth matrix are not significantly correlated $(r=-0.03$, Mantel $t=-0.30, P=\mathrm{NS})$. Finally, a partial correlation between the depth matrix and the $M$ matrix with geographical distance held constant was also not significant $(r=-0.19$, Mantel $t=-1.75, P=\mathrm{NS})$. The partial correlation of the depth matrix with the $D$ matrix holding geographical distance constant is also not significant $(r=0.51$, Mantel $t=0.407$, $P=\mathrm{NS})$. These analyses and the general lack of correspondence between the dendrogram based on genetic distance (Fig. 3a) and depth (Fig. 3b) do not lend support to the hypothesis that age or depth of blueholes has contributed to the pattern of genetic diversity observed among the bluehole populations of G. hubbsi.

Second for each population, the average genetic distance to all other populations was calculated. If deep blueholes were colonized before shallow blueholes, the average genetic distance should be higher in deeper blueholes because they have been isolated longer. Indeed, a positive correlation is observed between the mean genetic distance and age of the bluehole $(r=0.58, P=0.029)$. This correlation, however, does not distinguish between the time at which blueholes were colonized and the pattern of colonization. It indicates that deeper blueholes may have been founded earlier (shallow blueholes could not), but does not indicate that populations in deeper blueholes were the source of populations in other, shallower sites. The absence of any strong

(c) The Genetical Society of Great Britain, Heredity, 80, 336-346. 
correspondence between the depth/distance dendrogram and genetic distance (see above) suggests that, in general, the populations in deeper blueholes are sinks rather than sources.

Regardless of this, some sites may have been sources for the other populations. To test for this possibility, the correlation between the genetic distance from each bluehole to all other sites and the geographical distance from that site to all others (Table 4) were examined. If any of the populations are sources from which other populations were founded, the correlation should be positive and significant. In 11 of 14 comparisons, the correlation is negative.

Third, the distribution of alleles was examined. If deep blueholes are a source from which shallow bluehole populations were founded, the shallow blueholes should possess a subset of the alleles observed in the deeper bluehole populations. The distribution of alleles does not support this pattern; 64 per cent of the populations in shallow blueholes possess unique alleles not observed in the deeper

Table 3 Pairwise comparisons of population structure, geographical distance and depth between Gambusia hubbsi populations on Andros Island. (a) Geographical distance between sites below diagonal and number of migrants per generation $(M)$ above diagonal. (b) Nei's unbiased genetic distance $(D)$ above diagonal. Below diagonal is the depth at which the most recent common ancestor may have colonized each bluehole as they filled with water during the past 17000 years (see Fig. 3b). Surface-water sites (Lime Pond and London Creek) are not included in the depth analysis because the time at which the sites were created is unknown

\begin{tabular}{|c|c|c|c|c|c|c|c|c|c|c|c|c|c|c|c|c|}
\hline Site & Arch & Cous & ETL & EW3 & Geo & Ken & LP & $\mathrm{LC}$ & NG1 & NG2 & NG3 & NG4 & NG5 & Stal & Voy & WTL \\
\hline \multicolumn{17}{|l|}{ (a) } \\
\hline Archie's & & 0.06 & 1.38 & 13.65 & 4.12 & 0.19 & 2.67 & 0.58 & 0.6 & 0.74 & 0.88 & 0 & 3.15 & 0.24 & 3.83 & 1.99 \\
\hline Cousteau's & 14.0 & & 0.08 & 0.10 & 0.17 & 2.95 & 0.11 & 0.53 & 0.51 & 0.32 & 0.15 & 0.04 & 0.12 & 0.20 & 0.08 & 0.27 \\
\hline East Twin L. & 18.1 & 9.5 & & 2.75 & 2.55 & 0.22 & 1.85 & 0.84 & 0.61 & 0.80 & 0.89 & 0.87 & 2.09 & 0.25 & 2.00 & 1.77 \\
\hline EW3 & 34.8 & 47.4 & 46.2 & & 12.65 & 0.24 & 8.18 & 0.65 & 0.78 & 1.00 & 0.95 & 7.23 & 8.41 & 0.24 & 9.88 & 2.38 \\
\hline George's & 14.5 & 1.1 & 10.4 & 48.2 & & 0.38 & 54.90 & 1.11 & 1.26 & 1.80 & 1.68 & 2.61 & 5.16 & 0.30 & 6.19 & 4.83 \\
\hline Ken's & 17.0 & 17.1 & 10.6 & 36.9 & 36.9 & & 0.32 & 1.18 & 1.17 & 0.82 & 0.30 & 0.14 & 0.19 & 0.28 & 0.23 & 0.52 \\
\hline Lime Pond & 0.3 & 13.8 & 17.9 & 35.1 & 35.1 & 17.1 & & 1.04 & 0.95 & 1.52 & 1.27 & 1.59 & 2.60 & 0.29 & 4.05 & 4.12 \\
\hline London Creek & 5.0 & 16.3 & 17.6 & 31.2 & 17.0 & 13.7 & 5.2 & & 1.59 & 1.75 & 0.69 & 0.42 & 0.62 & 0.34 & 0.66 & 1.36 \\
\hline NG1 & 15.9 & 2.0 & 10.2 & 49.4 & 1.4 & 18.7 & 15.6 & 18.3 & & 2.19 & 0.67 & 0.44 & 0.88 & 0.41 & 0.68 & 1.38 \\
\hline NG2 & 16.6 & 2.6 & 9.2 & 49.7 & 2.4 & 18.2 & 16.3 & 18.7 & 1.3 & & 0.79 & 0.47 & 0.97 & 0.37 & 0.88 & 2.08 \\
\hline NG3 & 15.0 & 1.9 & 7.7 & 47.7 & 2.7 & 16.1 & 14.8 & 16.8 & 2.7 & 2.2 & & 0.61 & 1.29 & 0.32 & 1.11 & 1.91 \\
\hline NG4 & 17.8 & 5.2 & 13.4 & 52.0 & 4.1 & 22.1 & 17.6 & 20.8 & 3.4 & 4.2 & 6.1 & & 2.15 & 0.18 & 2.20 & 1.35 \\
\hline NG5 & 25.6 & 15.2 & 7.5 & 52.3 & 15.9 & 15.4 & 25.5 & 25.0 & 15.1 & 13.9 & 13.3 & 17.4 & & 0.27 & 3.91 & 2.03 \\
\hline Stalactite & 15.3 & 10.2 & 3.9 & 3.9 & 42.2 & 7.3 & 15.2 & 14.1 & 11.6 & 11.0 & 8.9 & 15.0 & 10.9 & & 0.27 & 0.36 \\
\hline Voy’s & 3.9 & 13.1 & 15.2 & 15.2 & 34.4 & 13.1 & 4.0 & 3.1 & 15.1 & 15.6 & 13.7 & 17.7 & 22.7 & 11.9 & & 2.35 \\
\hline West Twin L. & 18.1 & 9.7 & 0.3 & 0.3 & 46.0 & 10.3 & 18.0 & 17.5 & 10.5 & 9.6 & 8.0 & 13.7 & 7.5 & 3.7 & 15.1 & \\
\hline \multicolumn{17}{|l|}{ (b) } \\
\hline Archie's & & 0.029 & 0.001 & 0 & 0.001 & 0.021 & 0 & 0.010 & 0.010 & 0.006 & 0.007 & 0 & 0.001 & 0.042 & 0 & 0.003 \\
\hline Cousteau's & 87 & & 0.030 & 0.027 & 0.024 & 0.001 & 0.023 & 0.011 & 0.011 & 0.014 & 0.037 & 0.029 & 0.031 & 0.044 & 0.030 & 0.023 \\
\hline East Twin L. & 87 & 67 & & 0.001 & 0.002 & 0.022 & 0.001 & 0.009 & 0.011 & 0.006 & 0.008 & 0.001 & 0.002 & 0.043 & 0.001 & 0.004 \\
\hline EW3 & 20 & 87 & 87 & & 0 & 0.019 & 0 & 0.009 & 0.008 & 0.005 & 0.006 & 0 & 0 & 0.039 & 0 & 0.003 \\
\hline George's & 87 & 13 & 87 & 87 & & 0.015 & 0 & 0.007 & 0.006 & 0.004 & 0.005 & 0.001 & 0.001 & 0.037 & 0.001 & 0.002 \\
\hline Ken's & 11 & 87 & 87 & 20 & 87 & & 0.015 & 0.006 & 0.007 & 0.008 & 0.026 & 0.021 & 0.022 & 0.039 & 0.021 & 0.016 \\
\hline Lime Pond & - & - & - & - & - & - & & 0.007 & 0.008 & 0.004 & 0 & 0.002 & 0 & 0.039 & 0.001 & 0.002 \\
\hline London Creek & - & - & - & - & - & - & & & 0.006 & 0.005 & 0.014 & 0.001 & 0.010 & 0.038 & 0.010 & 0.008 \\
\hline NG1 & 87 & 13 & 67 & 87 & 11 & 87 & - & - & & 0.004 & 0.015 & 0.001 & 0.008 & 0.031 & 0.010 & 0.007 \\
\hline NG2 & 87 & 13 & 67 & 87 & 11 & 87 & - & - & 9 & & 0.012 & 0.006 & 0.006 & 0.036 & 0.006 & 0.006 \\
\hline NG3 & 87 & 15 & 67 & 87 & 15 & 87 & - & - & 15 & 15 & & 0.007 & 0.005 & 0.042 & 0 & 0.003 \\
\hline NG4 & 87 & 14 & 67 & 87 & 14 & 87 & - & - & 14 & 14 & 15 & & 0.001 & 0.042 & 0.001 & 0.004 \\
\hline NG5 & 87 & 67 & 43 & 87 & 67 & 87 & - & - & 67 & 67 & 67 & 67 & & 0.038 & 0.001 & 0.004 \\
\hline Stalactite & 87 & 67 & 52 & 87 & 67 & 87 & - & - & 67 & 67 & 67 & 67 & 52 & & 0.041 & 0.039 \\
\hline Voy's & 5.5 & 87 & 87 & 20 & 87 & 11 & - & - & 87 & 87 & 87 & 87 & 87 & 87 & & 0.003 \\
\hline West Twin L. & 87 & 67 & 43 & 87 & 67 & 87 & - & - & 67 & 67 & 67 & 67 & 39 & 43 & 87 & \\
\hline
\end{tabular}




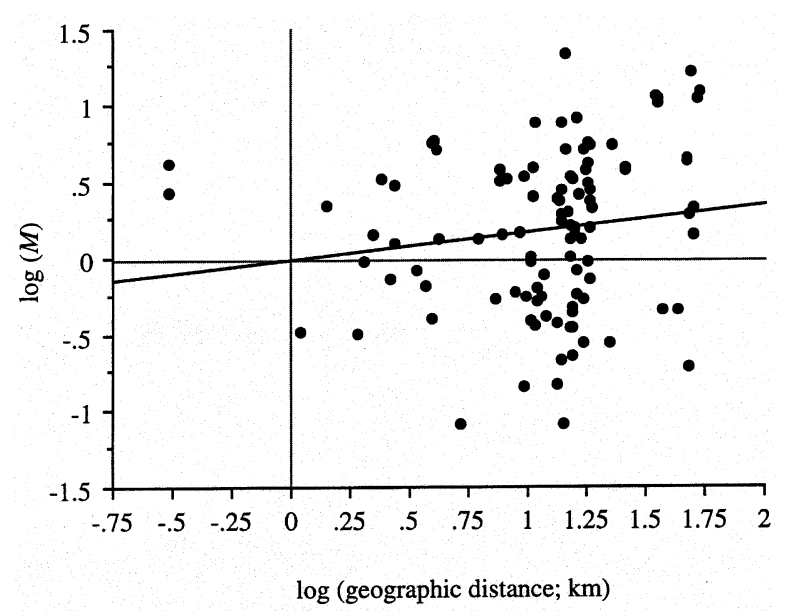

Fig. 2 Scatterplot of migration ( $M$; Slatkin's analogue of $\mathrm{Nm}$ ) calculated from allozyme frequencies and geographical distance among 16 populations of Gambusia hubbsi on Andros Island. A negative and significant correlation is expected if a pattern of isolation-by-distance is present.

bluehole populations. It is unlikely that sampling errors account for this observation because our sample size is large.

\section{Discussion}

Relative to other species of fish, genetic structure among bluehole populations of $G$. hubbsi in this study is among the highest reported $\left(F_{\mathrm{ST}}=0.38-0.4\right), \quad$ similar to genetic structure observed among freshwater populations in highly disjunct habitats, such as different river systems, lakes separated by significant geographical distances or geological barriers (Ward et al., 1994), or islands (e.g. Johnson et al., 1994; Johnson \& Black, 1995). High levels of population structure reflect the low average heterozygosity and a relatively large number of low-frequency alleles unique to a single population or shared among a small number of the populations. Because of the high levels of genetic structure and lack of isolation-by-distance, the population structure observed is most closely described by an island model (Wright, 1973), in which discrete populations receive migrants independently from a panmictic source population. However, Slatkin (1993) suggested that a pattern of isolationby-distance may not be detected by genetic data such as ours if the measurement of geographical distance among localities does not reflect actual migration routes or if historical population dynamics vary considerably among the populations.

\section{Are geographical distances representative of migration routes?}

It is unlikely that migration routes through surface water are shorter among more geographically distant blueholes. Many of the blueholes studied are geographically separated by several kilometres or more (Table 3a), and surface water is common enough that routes between distant populations must be much longer than routes between closer populations. If underground caverns connecting blueholes exist, travel through them must be very limited. The presence of an interface between salt and freshwater, called a halocline (Mylroie \& Carew, 1995), below which the water becomes highly saline and anoxic (L. Brown unpubl. data), limits the habitability to roughly $15 \mathrm{~m}$ below the surface. Many of the blueholes are also such great distances from one another that it is unlikely that connecting caverns are common enough to explain the lack of isolation-by-distance observed. For example, in seven of the 16 pairwise comparisons of EW3 with other populations, $M$ is above one, despite its relatively remote location (Table $3 \mathrm{a}$ ). Other comparisons between blueholes also indicate that this possibility is very unlikely.

\section{Does age of blueholes affect patterns of genetic variation?}

Geographical distance measures also do not account for the historical availability of blueholes. During the past 15000 years, sea levels have risen more than 100 m (Boardman et al., 1989; Fairbanks, 1989; Mylroie \& Carew, 1995). Thus, at the height of the most recent glacial maximum, blueholes were dry. Subsequently they may have been colonized by $G$. hubbsi as they filled with water. The data were examined for an effect of bluehole depth on genetic differentiation and patterns of relationship among the populations and found no consistent support for this hypothesis. Although Cousteau's, Stalactite and Ken's blueholes, three of the deeper blueholes sampled, have significantly higher values of Nei's $D$ (Table 3b), the general pattern of historical divergence and depth of a bluehole is not confirmed by the phylogenetic analysis. Furthermore, there is no indi- 
(a)

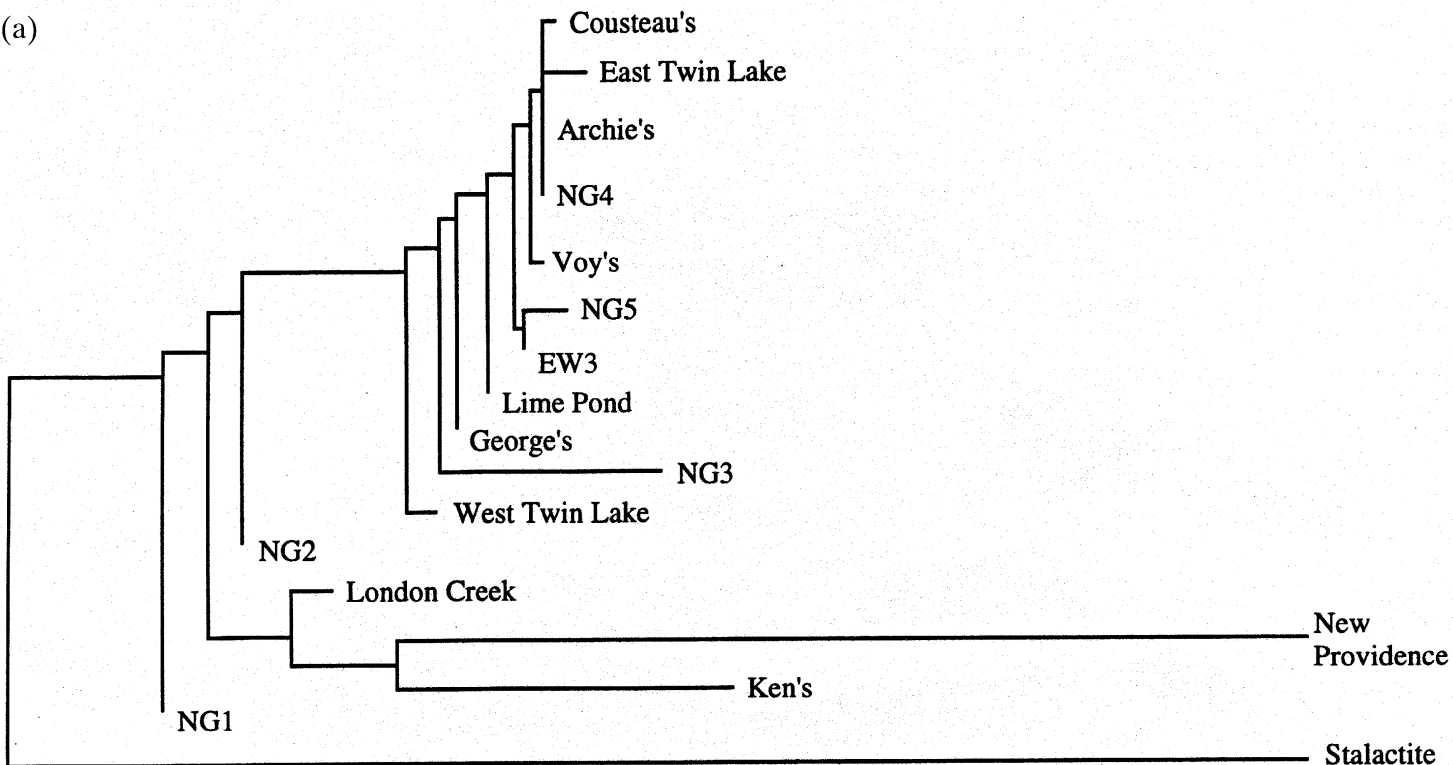

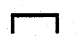

$\begin{array}{ll}0 & 0.001\end{array}$

Site: Depth (m)

(b)
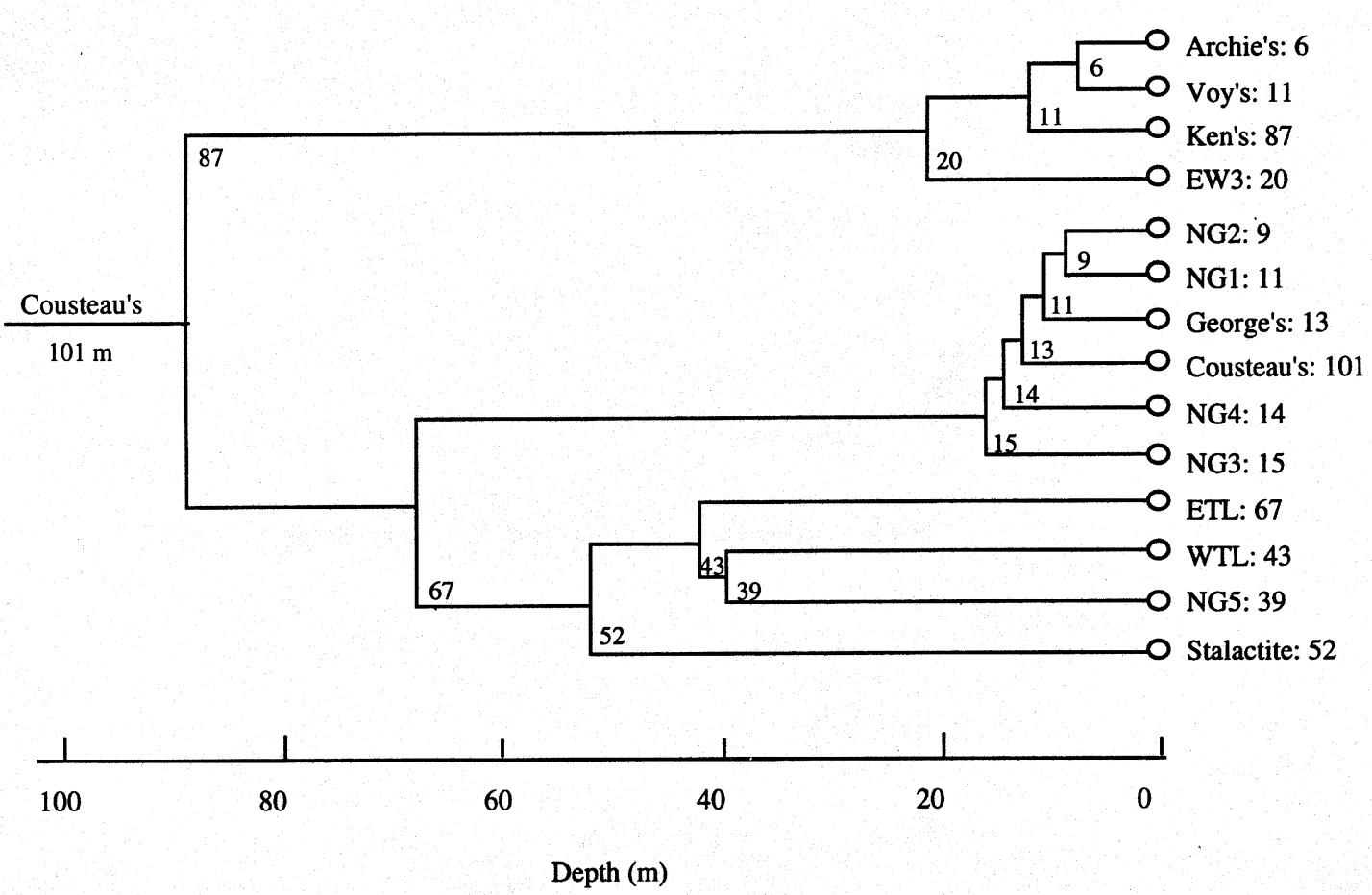

Fig. 3 (a) Neighbour-joining tree for 17 populations of Gambusia hubbsi. Genetic distance calculated by Nei's method from 32 allozyme loci. (b) Hypothetical phylogeny of G. hubbsi populations in blueholes based on depth of the bluehole (representing the time at which it became available for colonization) and geographical distance of closest possible source population (see text for explanation).

(c) The Genetical Society of Great Britain, Heredity, 80, 336-346. 
Table 4 Spearman rank correlations between Nei's unbiased genetic distance $(D)$ for Gambusia hubbsi populations on Andros Island, and geographical distance from each bluehole to other blueholes $(n=14)$. The analysis uses each bluehole as a reference. If any individual bluehole population of $G$. hubbsi is a source from which all other blueholes are colonized, the correlation should be positive and significant

\begin{tabular}{lc}
\hline Bluehole & Rank correlation \\
\hline Archie's & -0.304 \\
Cousteau's & 0.036 \\
East Twin Lake & $-0.609^{*}$ \\
EW3 & -0.065 \\
George's & -0.465 \\
Ken's & $-0.638^{*}$ \\
NG1 & 0.027 \\
NG2 & 0.073 \\
NG3 & -0.195 \\
NG4 & -0.368 \\
NG5 & $-0.650^{*}$ \\
Stalactite & -0.260 \\
Voy's & -0.435 \\
West Twin Lake & $-0.625^{*}$ \\
\hline
\end{tabular}

${ }^{*} P<0.05$.

cation that any of the blueholes are sources from which other bluehole populations have been derived. Rather, the populations appear to be 'sinks'.

\section{Do historical population dynamics affect genetic variation?}

Several theoretical and empirical studies have demonstrated that population dynamics may have a significant influence on $F_{\mathrm{ST}}$ that can obscure a simple interpretation as a balance between genetic drift and gene flow (e.g. Slatkin, 1977, 1993; Whitlock, 1990; Whitlock \& McCauley, 1992; Nürnberger \& Harrison, 1995). Periodic extinction and recolonization events can produce markedly different allele frequencies in the face of high gene flow (Slatkin, 1977; Whitlock \& McCauley, 1992). Bottlenecks are also particularly effective in amplifying measures of $F_{\mathrm{ST}}$ because the founding propagule is generated in situ rather than from a panmictic migrant pool (Slatkin, 1977; Whitlock \& McCauley, 1992). For example, Nürnberger and Harrison's (1995) markrecapture studies of whirligig beetle populations demonstrated that extinction-recolonization events inflated $F_{\mathrm{ST}^{-}}$-values of mtDNA variation in local populations. On a larger geographical scale, gene flow was high and acted as an important homogeniz- ing force. Gaggiotti (1996) also demonstrated theoretically that local genetic structure can be profoundly influenced by stochastic migration rates among source-sink populations.

Measurement of average heterozygosity may provide some insight into the potential impact of population dynamics on genetic variability (Maruyama \& Fuerst, 1985; Gaggiotti, 1996). Mean heterozygosities of $G$. hubbsi populations $[H=0.024$ (range 0.00-0.06); Table 1] are below average for fish. Nevo et al. (1984) reported an average heterozygosity for 195 fish species of 0.05 in which an average of 25.97 loci per species were screened. Indeed, two species of mosquitofish from the southeastern United States ( $G$. affinis and $G$. holbrookii) exhibit among the highest levels of genetic variability recorded

for any fish species (Wooton et al., 1988; Smith et al., 1989; Hernandez-Martich \& Smith, 1990). For example, Hernandez-Martich \& Smith (1990) reported that $37-55$ per cent of surveyed loci were polymorphic, and heterozygosities ranged from 0.087 to 0.160 in a large survey of $G$. holbrookii populations in the south-eastern United States.

We cannot exclude the possibility that the low levels of heterozygosity in the $G$. hubbsi populations in our study are an ancestral state. In fact, levels of heterozygosity in two surface-water populations (Lime Pond and London Creek) are also very low, and population structure between them is high and marginally significant $(\theta=0.244 ; 95$ per cent $\mathrm{CI}=0.272$ to -0.003$)$. Thus, bluehole populations may have been derived from heterogenous surfacewater populations with low levels of heterozygosity. However, the effects of bottlenecks within blueholes can also not be excluded as a significant influence on heterozygosity. Although this effect may be less pronounced in Gambusia because multiply inseminated females (Chesser et al., 1984) sometimes colonize new habitats more often than males (Brown, 1985), it must still be considered as a potential influence on levels of genetic variation. In fact, heterozygosity is extremely low in some populations, yet population structure is nearly twice that observed among surface-water populations, suggesting that bottlenecks may have occurred at some time in the history of many bluehole populations of $G$. hubbsi.

We have not yet been able to test the effects of population dynamics on genetic variation directly by measuring population size in the field because of high mortality of males during marking, a phenomenon also observed in G. affinis by Winkler (1975). Measuring the diameter of blueholes as a rough indication of population size is not a reliable option. 
Nevertheless, many years of field work and observation of these fish have given us a general feel for population sizes and fluctuations. Although extinction and recolonization may occur routinely in some blueholes (e.g. we have observed West Twin Lake with no fish on one occasion and many fish on other occasions), other blueholes appear to sustain relatively constant and large population sizes of $G$. hubbsi (e.g. Cousteau's, Stalactite). Our experience suggests that the effects of phenomena, such as small founding events, extinction and recolonization and population bottlenecks, may differ dramatically for each bluehole. The remote location of the blueholes and sparse human populations on Andros Island make human transport of fish among the blueholes highly unlikely. However, it has not been possible to identify any clear geographical characteristics associated with 'stable' and fluctuating' populations or colonization routes. The development of marking techniques to measure population density directly and statistical techniques to estimate effective population size reliably using genetic markers may provide more insight into the relative impact of ancestral variation vs. demography on genetic variation in $G$. hubbsi populations inhabiting blueholes on Andros Island.

\section{Conclusion}

There was no evidence that any of the bluehole populations are sources from which other blueholes were founded. Rather, they appear to be 'sinks' into which migrants enter very rarely. Clearly, gene flow among populations of $G$. hubbsi in the blueholes studied on Andros Island is rare, and drift is a dominating force in determining the genetic structure of populations. This provides an environment for selection to act on phenotypes within each unique bluehole ecosystem to produce specialists. Indeed, phenotypic divergence among populations of $G$. hubbsi on Andros Island is extreme, higher than reported among any Poeciliid (unpubl. data; Brown \& Downhower, 1993). The degree to which migration into blueholes and population dynamics may affect the rate and action of selection within populations will be a profitable line of future research.

\section{Acknow ledgements}

We thank Maurice Isaacs and Eric Carey of the Department of Agriculture and Fisheries, Bahamas, for providing collection permits. Chris Russell and Gladstone Ferguson of the Lands and Surveys Department, Bahamas, provided maps. Cadrington
Coleby of the Department of Water and Sewage, Bahamas, helped locate and collect mosquitofish. Pericles Maillis, Sandra Buckner and other members of the Bahamas National Trust, Bahamas, helped in numerous ways. Richard and Hortense Riley provided excellent accommodation on Andros Island. We also thank Earthwatch volunteers and especially M. Matsui for help locating and measuring the depths of blueholes. C. Aquadro, R. Harrison, M. Noor, P. Parker and A. Snow provided thoughtful and stimulating discussions and/or read drafts of the paper. M. Boardman and R. Carew provided excellent advice about Andros Island geology. Funding was provided by Sigma Xi, The National Geographical Society, EarthWatch, Inc., the Graduate School of The Ohio State University and NSF/PCRB grant DEB-9300065 to P.A.F.

\section{References}

BLACK, M. B., LUTZ, R. A. AND VRIJENHOEK, R. C. 1994. Gene flow among vestimentiferan tube worm (Riftia pachyptila) populations from hydrothermal vents of the eastern Pacific. Mar. Biol., 120, 33-39.

BOARDMAN, M., NEUMANN, A. C. AND RASMUSSEN, K. A. 1989. Holocene sea level in the Bahamas. In: Mylroie, J. E. (ed.) Proceedings of the Fourth Symposium on the Geology of the Bahamas, pp. 45-52. Bahamas Field Station, San Salvador.

BROWN, K. 1985. Demographic and genetic characteristics of dispersal in the mosquitofish, Gambusia affinis (Pisces, Poeciliidae). Copeia, 1985, 597-612.

BRown, L. P. AND DOWNHOWER, J. F. 1993. The eyes of Andros. Bahamas Naturalist, 7, 5-10.

CHESSER, R. K., SMITH, M. W. AND SMITH, M. H. 1984. Biochemical genetics of mosquitofish. III. Incidence and significance of multiple insemination. Genetica, 64, 7-81.

FAIRBANKS, R. G. 1989. A 17000 year glacio-eustatic sea level record: influence of glacial melting rates on the Younger Dryas event and deep-ocean circulation. Nature, 342, 637-642.

Gaggiotti, o. E. 1996. Population genetic models of source-sink metapopulations. Theor. Pop. Biol., 50, 178-208.

HERNANDEZ-MARTICH, J. D. AND SMITH, M. H. 1990. Patterns of genetic variation in eastern mosquitofish (Gambusia holbrookii Girard) from the piedmont and coastal plain of three drainages. Copeia, 1990, 619-630.

JOHNSON, M. S. AND BLACK, R. 1995. Neighbourhood size and the importance of barriers to gene flow in an intertidal snail. Heredity, 75, 142-154.

JOHNSON, M. S., WATTS, R. J. AND BLACK, R. 1994. High levels of genetic subdivision in peripherally isolated populations of the atherinid fish Craterocephalus Capreoli in the Houtman Abrolhos Islands, Western Australia. Mar. Biol., 119, 179-184. 
KUMAR, S., TAMURA, K. AND NEI, M. 1993. MEGA. Molecular Evolutionary Genetic Analysis. Version 1.01. The Pennsylvania State University, University Park, PA.

LEGENDRE, P. AND VAUDOR, A. 1991. The R Package. Multidimensional Analysis, Spatial Analysis. Départment biologiques, Université de Montreal, Montreal, Canada.

LEVENE, H. 1949. On a matching problem arising in genetics. Ann. Math. Stat., 20, 91-94.

MARUYAMA, T. AND FUERST, P. A. 1985. Population bottlenecks and nonequilibrium models in population genetics. II. Number of alleles in a small population that was formed by means of a recent bottleneck. Genetics, 111, $675-689$.

MEFFE, G. K. AND SNELSON, F. F., JR. 1989. Ecology of livebearers, In: Meffe, G. K. and Snelson, F. F. (eds) Ecology and Evolution of Livebearing Fishes (Poeciliidae), pp. 1-25. Prentice Hall, NJ.

MORIzOT, c. 1993. Handbook of Isozyme Genetics. CRC Press, Boca Raton, FL.

MURPHEY, W., SITES, J. W., JR., BUTH, D. G. AND HAUFLER, C. H. 1996. Proteins: isozyme electrophoresis, In: Hillis, D. M., Moritz, C. and Mable, B. K. (eds) Molecular Systematics, pp. 51-116. Sinauer Associates, Sunderland, MA.

MYLROIE, J. E. AND CAREW, J. L. 1988. Solution conduits as indicators of late Quaternary sea level position. Quat. Sci. Rev., 7, 55-64.

MYLROIE, J. E. AND CAREW, J. L. 1995. Karst development on carbonate islands, In: Budd, D. A., Saller, A. and Harris, P.M. (eds) Unconformities in Carbonate Strata, Their Recognition and Significance of Associated Porosity. Mem. Am. Ass. Petrol. Geol., 63, 55-76.

MYLROIE, J. E., CAREW, J. L. AND MOORE, A. I. 1997. Blue holes, definition and genesis. Carbonate Evaporates, 10, $225-233$

NEI, M. 1978. Estimation of average heterozygosity and genetic distance from a small number of individuals. Genetics, 89, 583-590.

NEVO, E., BEILES, A. AND BEN-SHLOMO, R. 1984. The evolutionary significance of genetic diversity, ecological, demographic and life history correlates. In: Levin, S. (ed.) Evolutionary Dynamics of Genetic Diversity, pp. 13-213. Springer, Berlin.

NÜRNBERGER, B. AND HARRISON, R. G. 1995. Spatial population structure in the whirligig beetle Dineutus assimilis: evolutionary inferences based on mitochondrial DNA and field data. Evolution, 49, 266-275.

PASTEUR, N. 1988. Practical Isozyme Genetics. Ellis Harwood Ltd, Halstead Press, New York.

PROUd-LOVE, G. S. 1984. Preliminary observations on the biology of island blueholes, Andros Island. Trans. British Cave Res. Ass., 11, 53-56.
RAUCHENBERGER, M. 1989. Systematics and biogeography of the genus Gambusia (Cyprinodontiformes, Poeciliidae). Am. Mus. Novitates, 2951, 1-74.

SAITOU, N. AND NEI, M. 1987. The neighbor-joining method. A new method for reconstructing phylogenetic trees. Mol. Biol. Evol., 4, 406-425.

SELANDER, R. K., SMITH, M. H., YANG, S. Y., JOHNSON, W. E. AND GENTRY, J. R. 1971. Biochemical polymorphism and systematics in the genus Peromyscus. I. Variation in the old-field mouse (Peromyscus polionotus). Studies in Genetics VI. University of Texas Publications, 7103, 49-90.

SLATKIN, M. 1977. Gene flow and genetic drift in species subject to frequent local extinctions. Theor. Pop. Biol., 12, 253-262.

SLATKIN, M. 1993. Isolation by distance in equilibrium and non-equilibrium populations. Evolution, 47, 264-279.

SMITH, M. H., SCRIBNER, K. T., HERNANDEZ, J. D. AND wooton, м. с. 1989. Demographic, spatial, and temporal genetic variation in Gambusia, In: Meffe, G. K. and Snelson, F. F., Jr. (eds) Ecology and Evolution of Livebearing fishes (Poeciliidae), pp. 235-257. Prentice Hall, New Jersey.

SWOFFORD, D. AND SElANDER, R. K. 1981. BIOSYs-1. $A$ Computer Program for the Analysis of Variation in Population Genetics and Biochemical Systematics. Release 1.7. University of Illinois, Urbana, IL.

WARD, R. D., WOODWARD, M. AND SKIBINSKI, D. O. F. 1994. A comparison of genetic diversity in marine, freshwater, and anadromous fishes. J. Fish Biol., 44, 213-232.

WEIR, B. S. AND COCKERHAM, C. C. 1984. Estimating $F$-statistics for the analysis of population structure. Evolution, 38, 1358-1370.

whitLock, M. C. 1990. Temporal fluctuations in demographic parameters and the genetic variance among populations. Evolution, 46, 608-615.

WHITLOCK, M. C. AND MCCAULEY, D. E. 1992. Some population genetic consequences of colony formation and extinction; genetic correlations within founding groups. Evolution, 44, 1717-1724.

WINKLER, P. 1975. Thermal tolerance of Gambusia affinis (Teleostei, Poeciliidae) from a warm spring. I. Field tolerance under natural spring conditions. Phys. Zool., 48, 367-377.

WOOTON, M. C., SCRIBNER, K. T. AND SMITH, M. H. 1988. Genetic variability and systematics of Gambusia in the southeastern United States. Copeia, 1988, 283-289.

WRIGHT, s. 1973. The Origin of the F-statistics for Describing the Genetic Aspects of Population Structure. Population Genetics Monographs, Vol. 3, Genetic Structure of Populations. University of Hawaii Press, Honolulu. 